\title{
TLC-Densitometry Analysis of Indole Compounds in Mycelial Culture of Imleria badia and Agaricus bisporus Enriched with Precursors - Serine or Anthranilic Acid
}

\author{
Włodzimierz Opoka $^{1^{*}}$, Katarzyna Kała ${ }^{2}$, Remigiusz Krężałek ${ }^{2}$, Katarzyna Sułkowska-Ziaja ${ }^{2}$, \\ Anna Maślanka ${ }^{1}$ and Bożena Muszyńska ${ }^{2}$ \\ ${ }^{1}$ Department of Inorganic Chemistry, Faculty of Pharmacy, Jagiellonian University Medical College, Kraków, Poland \\ ${ }^{2}$ Department of Pharmaceutical Botany, Faculty of Pharmacy, Jagiellonian University Medical College, Kraków, Poland
}

Received: 14 May 2017; accepted: 05 June 2017

\begin{abstract}
Agaricus bisporus and Imleria in vitro cultures were cultivated on modified Oddoux medium, and Oddoux medium was enriched with serine or anthranilic acid. Serine or anthranilic acid was used at the concentrations of $0.1,0.25$, 0.5 , and $0.75 \mathrm{~g} / \mathrm{L}$ of medium. Determination of indole compounds in the obtained biomass was carried out using thin-layer chromatography (TLC) with densitometric detection. In every analyzed sample, presence of serine or anthranilic acid was studied. Comparison of the results obtained for the treatment and control samples allowed us to determine the optimum concentration of serine or anthranilic acid in the medium in order to obtain biomass with increased content of indole compounds. A. bisporus with addition of anthranilic acid or serine to the medium at the concentration of $0.5 \mathrm{~g} / \mathrm{L}$ was the most beneficial. In the case of Imleria badia, anthranilic acid at the concentration of $0.5 \mathrm{~g} / \mathrm{L}$ was the most optimal. This is the first report demonstrating the content of indole derivatives in biomass affected by their precursors (serine or anthranilic acid). The study indicates that modification of the medium can provide satisfactory results, and it is worth to search for its new, improved compositions.
\end{abstract}

Keywords: Agaricus bisporus, Imleria badia, indole compounds, serine, anthranilic acid, mycelial in vitro cultures

\section{Introduction}

Mushrooms as cosmopolitan organisms are present in the human environment. Also, we should remember about symbiotic species that coexist with many plants providing mutual benefits. Numerous edible species among mushrooms have aroma and taste. Edible mushrooms are a good source of many essential compounds, such as amino acids, lipids, phenolic and indole compounds, flavonoids, fiber, vitamins, and macro- and microelements [1, 2].

A number of chemical compounds occurring in fruiting bodies of mushrooms include indole derivatives such as L-tryptophan, 5-hydroxy-L-tryptophan, tryptamine, and others. Indole compounds act as neurotransmitters in the human organism and contribute to blood clotting or smooth muscle contraction, and their deficiency can lead to depressive disorders [3]; thereby, it is very important to provide these compounds with food in the amounts needed for the organism or their eventual supplementation.

So far, many mushroom species have been tested in terms of their indole content in both fruiting bodies derived from their natural condition and in biomass of mycelial cultures using solid or liquid medium. In this group of compounds, Muszyńska et al. carried out important studies [4-6]. The effect of addition of L-tryptophan to the liquid medium has also been studied on quantitative and qualitative composition of indole compounds in the obtained biomass [7].

Imleria badia is a species rich in antioxidant compounds, such as tocopherols and phenolic acids [8]. It contains vitamins especially from group B, as well as macro- and microelements $[9,10]$. In the fruiting bodies of I. badia, significant amounts of

\footnotetext{
* Author for correspondence: wlodzimierz.opoka@uj.edu.pl
}

phenolic acids, such as $p$-coumaric, cinnamic acid, or the most abundant protocatechuic acid, have been detected. Among other fungal species investigated at the same time, the highest total amount of phenolic acids was detected in I. badia [11].

Agaricus bisporus is a species characterized with a high capability to accumulate macro- and microelements from the environment, constituting a good source of zinc and selenium $[12,13]$. Among compounds classified as antioxidants, $\alpha$-tocopherols, $\beta$-carotenes, or phenolic compounds have been identified in A. bisporus. The overall antioxidant activity of this species of mushroom is higher than the abovementioned compounds; therefore, research continues on the detection of new antioxidant mechanisms of extracts [14]. The latest studies indicate on the presence of ergothionein in A. bisporus fruiting bodies, a naturally occurring amino acid containing imidazole ring and a sulfur atom.

In human, the highest concentration of ergothionein can be found in organs particularly susceptible to oxidative stress, e.g., liver, kidneys, or red blood cells. This compound has been identified as the most important substrate for organic cation transporter (OCTN1) that plays a role in distribution of L-carnitine. Mutations in gene coding OCTN1 have been identified, among others, in rheumatoid arthritis or Crohn's disease $[15,16]$. Sixteen weeks of regular consumption of $A$. bisporus significantly increased the concentration of ergothionein in the organism, which may be associated with a positive effect in individuals with metabolic syndrome [17]. Moreover, ergothionein exhibits anti-inflammatory and radioprotective activities $[1,15]$.

Lectins found in A. bisporus demonstrate antitumor activity. They enhance inhibition of HT-29 and Caco-2 colon adenocarcinoma, MCF-7 human breast cancer cells, rat mammary gland fibroblasts (Rama-27), or ocular melanoma cells. ABL (Agaricus

This is an open-access article distributed under the terms of the Creative Commons Attribution-NonCommercial 4.0 International License (https://creativecommons.org/licenses/by-nc/4.0/), which permits unrestricted use, distribution, and reproduction in any medium for non-commercial purposes, provided the original author and source are credited, a link to the CC License is provided, and changes - if any - are indicated. 
Bisporus Lectins) can inhibit DNA synthesis and antibody production in $\mathrm{T}$ and $\mathrm{B}$ lymphocytes and also inhibit the growth of human keratinocytes or papilloma [18-23]. The presence of indole compounds such as L-tryptophan, 5-hydroxy-L-tryptophan, melatonin, serotonin, tryptamine, and 5-methyltryptamine has also been found in A. bisporus [24].

The objective of this work was to determine the content of indole compounds in biomass from A. bisporus and I. badia in vitro cultures. The biomass was cultivated on liquid Oddoux medium modified by the addition of anthranilic acid or serine used as precursors of non-hallucinogenic indole compounds. The abovementioned compounds were applied at the following medium concentrations: $0.1,0.25,0.5$, and $0.75 \mathrm{~g} / \mathrm{L}$. In vitro culture on Oddoux liquid medium without modification was cultivated as control cultures. For indole compounds, analysis was used the thin-layer chromatography (TLC) method with densitometric detection. The optimum concentration of added compounds that would allow obtaining the appropriate qualitative and quantitative composition of indole compounds in the acquired lyophilized biomass from A. bisporus and I. badia in vitro cultures, was also investigated.

\section{Materials and Methods}

Mushroom materials. For in vitro cultivation, fruiting bodies of selected edible mushrooms species were used: I. badia (Fr.) Vizzini was collected across the years of 2014-2015 from the natural state in Brodła, and A. bisporus (J. E. Lange) Imbach was of commercial use. Muszyńska performed the taxonomic identification of collected young fungal fruiting bodies. Representative voucher specimens were deposited at the Department of Pharmaceutical Botany, Jagiellonian University Medical College, Kraków, Poland. In addition in vitro I. badia, A. bisporus cultures were cultivated on the modified Oddoux medium [25].

Experimental mycelial cultures. In vitro mycelial cultures were cultivated from explants derived from the hymenial part of fruiting bodies. They were degreased with $70 \%$ ethyl alcohol for $15 \mathrm{~s}$ followed by sterilization and for $1 \mathrm{~min}$ in $15 \%$ sodium chlorate(I) solution. The material was rinsed with redistilled water several times and transferred under laminar flow onto Oddoux solid medium with solidified agar. Cultures from solid medium were used to derive experimental cultures on a modified Oddoux liquid medium. The starting inoculum from the solid medium was $0.1 \mathrm{~g}$. The culture biomass obtained on solid medium was subcultured to $500 \mathrm{~mL}$ Erlenmeyer flasks containing $250 \mathrm{~mL}$ sterile liquid medium. The purpose of culturing on a liquid medium was to achieve the highest biomass yield for further analyzes. Biomass was obtained from cultures on Oddoux medium (control medium) and using the same medium but with serine addition at the concentration of $0.1,0.25,0.5$, and $0.75 \mathrm{mg} / \mathrm{L}$ liquid medium or anthranilic acid at the same concentrations. The cultures were shaken at a speed of $140 \mathrm{rpm} / \mathrm{min}$ using Altel shaker. Incubation of culture was carried out at $25 \pm 2{ }^{\circ} \mathrm{C}$ in a cycle that imitates the natural conditions (photoperiod: $16 \mathrm{~h}$ of light intensity $900 \mathrm{~lx} / 8 \mathrm{~h}$ in the dark). After 4 weeks of growth, in vitro biomass culture was separated from the liquid medium using Büchner funnel and microfiber filter, followed by washing with four times distilled water. The resulting biomass was immediately frozen and then lyophilized at $-40{ }^{\circ} \mathrm{C}$ using Freezone 4.5 lyophilizer (Labconco).

Reagents. Acetic acid, 1-butanol, and methanol were analytically pure grade, and they were purchased from Chempur (Piekary Ślaskie, Poland). The standards: tryptamine, 5-hydroxy-L-tryptophan and L-tryptophan, and precursors of indole compounds: anthranilic acid and serine (all of HPLC grade) were from Sigma-Aldrich (St. Louis, Mo, USA).

Reference standard solutions. The standard substances were weighed with an accuracy of $0.1 \mathrm{mg}$, and they were dissolved in methanol obtaining solutions of the following concentrations: tryptamine, $0.460 \mathrm{mg} / \mathrm{mL}$ and $0.070 \mathrm{mg} / \mathrm{mL}$; 5-hydroxy-L-tryptophan, $0.500 \mathrm{mg} / \mathrm{mL}$ and $0.040 \mathrm{mg} / \mathrm{mL}$; L-tryptophan, $0.460 \mathrm{mg} / \mathrm{mL}$ and $0.052 \mathrm{mg} / \mathrm{mL}$.

Apparatus. The applicators for the samples were the following: LINOMAT 4; Camag (Muttenz, Switzerland); densitometer TLC-Scanner 3 with WinCats software version 1.3.4; Camag (Muttenz, Switzerland); analytical scale of WWA $100 / \mathrm{C} / 1$ type with an accuracy of $0.1 \mathrm{mg}$ (RADWAG, Poland); microsyringe of a volume of $100 \mu \mathrm{L}$ (Hamilton Comp., USA); chromatographic chamber, $23 \mathrm{~cm} \times 7 \mathrm{~cm} \times 21 \mathrm{~cm}$ Camag (Muttenz, Switzerland); and TLC plates, aluminum sheets of a size of $20 \times 20 \mathrm{~cm}$ covered with silica gel with fluorescence agent 60 F254 MERCK (Darmstadt, Germany).

Chromatographic analysis. Experimental mycelial cultures on liquid medium provided good biomass yield, which allowed to obtain its appropriate amount and were sufficient for the extraction of indole compounds. The extraction was carried out via the percolation method according to Muszyńska et al. - a procedure for determination of indole compounds in mushrooms $[5,7,26]$. Weighted amounts of the lyophilized in vitro biomass culture of $A$. bisporus and I. badia were prepared. The material was placed in glass percolators and extracted four times with ether to remove lipid fraction. The biomass after extraction was dried and reextracted - percolation was carried out for $24 \mathrm{~h}$ using methanol. The resulting extracts were concentrated at $40{ }^{\circ} \mathrm{C}$ using evaporator, and the residue was placed in the crystallizers to evaporate.

Dry residue was dissolved in methanol and filtered through Whatman 3 MM filter paper. Furthermore, the filtrate was supplemented with methanol. Samples were purified using a syringe filter (Millex, Millipore Corporation, USA), transferred to Eppendorf tubes, and subjected for TLC with densitometric detection.

In the first step of the research, the conditions of analyzed substances separation were determined. The amount of $5 \mu \mathrm{L}$ of sample and $3 \mu \mathrm{L}$ of reference standard solutions was spread in a form of $1 \mathrm{~cm}$ wide bands on TLC $\mathrm{F}_{254}$ plates of $20 \mathrm{~cm} \times$ $20 \mathrm{~cm}$ size, and then, they were developed to the height of $15.0 \mathrm{~cm}$. Tryptamine $\left(R_{\mathrm{F}}=0.70\right)$, L-tryptophan $\left(R_{\mathrm{F}}=0.61\right)$, and 5-hydroxy-L-tryptophan $\left(R_{\mathrm{F}}=0.55\right)$ were determined using mobile phase composed of: butan-1-ol-glacial acetic acid-water (12:3:5, v/v/v) (Figure 1). Registration of stains of indole derivatives on chromatograms was done densitometrically at $\lambda=260 \mathrm{~nm}$ (Figure 2). Areas of peaks originating from tryptamine, 5-hydroxy-L-tryptophan, and L-tryptophan were used for calculation of the concentration, and they were compared to the peak areas of respective reference standards.

\section{Validation of TLC-densitometry method}

Reference standard solutions. Validation of the method was performed by determination of specificity, accuracy, precision, linearity, limit of detection, and limit of quantification [27].

Accuracy. Accuracy was determined based on sample analysis of known concentrations and comparing the results obtained by a validated method with true values, followed by calculation of the recovery percentage. Determinations were performed at three concentration levels: $80 \%, 100 \%$, and $120 \%$; for each of them, three repetitions were done.

Precision. Precision of the method was determined at three levels of substance concentrations in reference solutions: $50 \%$, $100 \%$, and $150 \%$. For each level of concentration, three repetitions were done. 


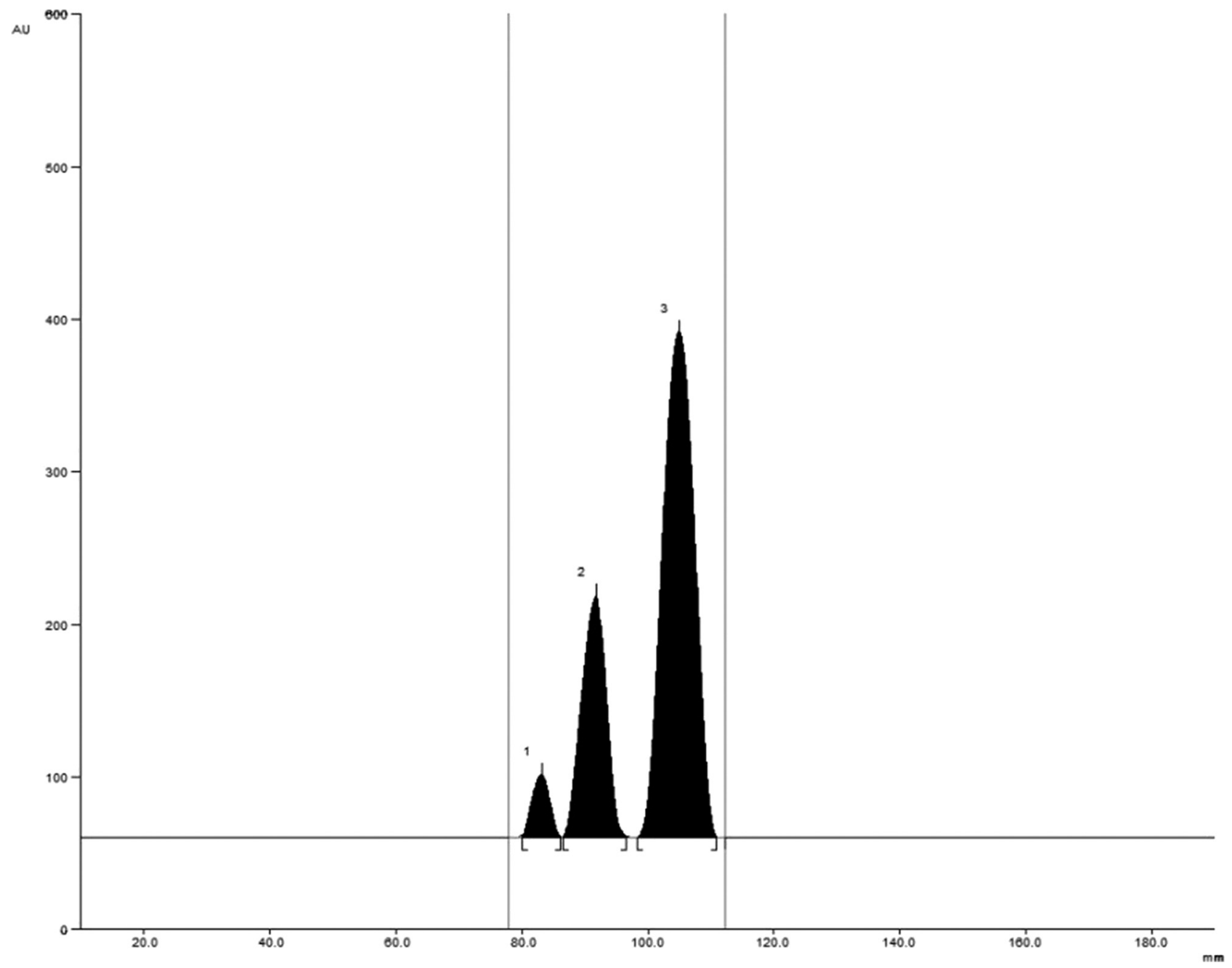

Figure 1. Representative densitogram of methanolic extract of Imleria badia biomass from in vitro culture enriched in 0.5 (g/L) anthranilic acid: 5-hydroxy-L-tryptophan (1), L-tryptophan (2), and tryptamine (3)

Linearity. Linearity was determined by comparing the relationship between peak area $\left(\mathrm{mm}^{2}\right)$ and amount of test substance applied to the plate $(\mu \mathrm{g} / \mathrm{spot})$. Two series of assays in the following concentration ranges were performed for each substances: from $0.14 \mu \mathrm{g} /$ spot to $1.40 \mu \mathrm{g} /$ spot for tryptamine, from $0.104 \mu \mathrm{g} / \mathrm{spot}$ to $1.560 \mu \mathrm{g} / \mathrm{spot}$ for 5-hydroxy-L-tryptophan, and from $0.080 \mu \mathrm{g} / \mathrm{spot}$ to $1.920 \mu \mathrm{g} / \mathrm{spot}$ for L-tryptophan (Table 1).

Limit of detection (LOD) and limit of quantification (LOQ). The limit of detection and limit of quantification were determined from the linearity in the following concentration ranges: from $0.140 \mu \mathrm{g} / \mathrm{spot}$ to $0.840 \mu \mathrm{g} / \mathrm{spot}$ for tryptamine, from $0.080 \mu \mathrm{g} / \mathrm{spot}$ to $0.800 \mu \mathrm{g} / \mathrm{spot}$ for 5 -hydroxy-L-tryptophan, and from $0.104 \mu \mathrm{g} /$ spot to $0.624 \mu \mathrm{g} / \mathrm{spot}$ for L-tryptophan, using the following formulas: $\mathrm{LOD}=3.3 \cdot S_{\mathrm{y}} / a, \mathrm{LOQ}=10 \cdot S_{\mathrm{y}} / a$, where $S_{\mathrm{y}}$ is estimation error and $a$, slope (Table 1$)$.

Substances determination. The amount of $5 \mu \mathrm{L}$ of sample and $3 \mu \mathrm{L}$ of reference standard solutions was spread in a form of $1 \mathrm{~cm}$ wide bands on TLC $F_{254}$ plates of $20 \mathrm{~cm} \times 20 \mathrm{~cm}$ size. Chromatograms were developed up to $15.0 \mathrm{~cm}$, in a chromatographic chamber saturated with mobile phase. Next, the plates were dried at room temperature. Densitometric registration was made at $260 \mathrm{~nm}$ wavelength.

Identification of indole compounds in the samples was performed using internal standards. Compounds were identified based on $R_{\mathrm{F}}$ for the stains of extracts under study from reference and samples. The quantification was done by comparison of area under peak and then recalculated for $100 \mathrm{~g}$ of lyophilized sample. Results obtained for examined substances are shown in Table 1. The validation of analytical methods provided a precise indication of the test substances.

\section{Results and Discussion}

The validation results presented in Table 1 indicate that the proposed method is characterized by high sensitivity; LOD is $0.042 \mu \mathrm{g}$ for tryptamine, $0.057 \mu \mathrm{g}$ for 5-hydroxy-L-tryptophan, and $0.037 \mu \mathrm{g}$ for L-tryptophan; LOQ was estimated at $0.129 \mu \mathrm{g}, 0.172 \mu \mathrm{g}$, and $0.112 \mu \mathrm{g}$ respectively. Percentage recovery of the studied compounds presented as mean values for three concentration levels is high and ranges from $96.82 \%$ to $101.69 \%$. Satisfactory precision determined for three concentration levels is confirmed by the values of variability coefficients RSD which are in the range from $0.40 \%$ to $2.38 \%$. Linearity for tryptamine, 5-hydroxy-L-tryptophan, and L-tryptophan was preserved in a wide range: from $0.140 \mu \mathrm{g} / \mathrm{spot}$ to $1.400 \mu \mathrm{g} / \mathrm{spot}$, from $0.080 \mu \mathrm{g} / \mathrm{spot}$ to $1.920 \mu \mathrm{g} / \mathrm{spot}$, and from $0.104 \mu \mathrm{g} /$ spot to $1.560 \mu \mathrm{g} / \mathrm{spot}$, respectively.

The coefficient of determination $R^{2}$ does not explicitly describe the linearity of the calibration method; thus, the linear and square fit was compared using Mandel's fitting test [28]. The test results indicate the inequality between the two models; hence, the square fit was chosen. The normality of the residual distribution was confirmed by the Shapiro-Wilk test. The results of the analysis using Durbin-Watson test showed no significant autocorrelation of random components of L-tryptophan. There is a positive autocorrelation of random components of 5-hydroxy-L-tryptophan and tryptamine square fit; however, 


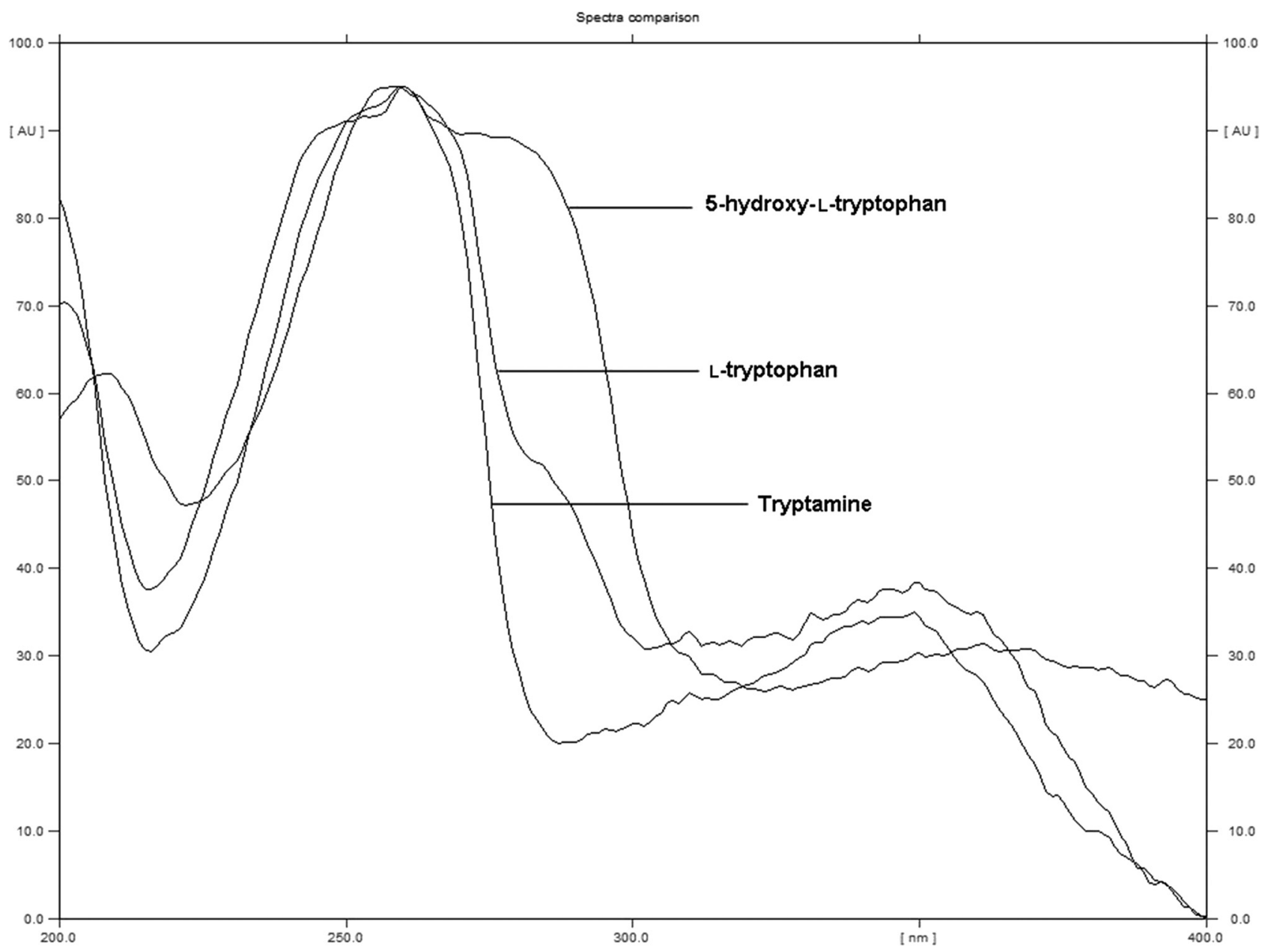

Figure 2. Absorption spectra of studied substances recorded directly from chromatograms

Table 1. Validation of the developed methods with statistical evaluation for TLC-densitometry method

\begin{tabular}{|c|c|c|c|}
\hline Validation parameters & Tryptamine & 5-Hydroxy-L-tryptophan & L-Tryptophan \\
\hline \multirow[t]{2}{*}{$\overline{R_{\mathrm{F}}}$} & $\sim 0.70$ & $\sim 0.55$ & $\sim 0.61$ \\
\hline & 0.042 & 0.057 & 0.037 \\
\hline \multirow[t]{2}{*}{ LOD $(\mu \mathrm{g} / \mathrm{spot})$} & $a=5344.1$ & $a=5395.1$ & $a=5333.6$ \\
\hline & $\mathrm{S}_{\mathrm{y}}=69.2$ & $S_{\mathrm{y}}=93.1$ & $S_{\mathrm{y}}=59.6$ \\
\hline \multirow[t]{2}{*}{ LOQ $(\mu \mathrm{g} /$ spot $)$} & 0.129 & 0.172 & 0.112 \\
\hline & $\bar{x}=96.82$ & $\bar{x}=99.27$ & $\bar{x}=98.07$ \\
\hline \multirow[t]{3}{*}{ Recovery $80 \%(\%)$} & $S_{\mathrm{x}}=0.530$ & $S_{\mathrm{x}}=0.775$ & $S_{\mathrm{x}}=0.725$ \\
\hline & $\mathrm{RSD}=0.54 \%$ & $\mathrm{RSD}=0.78 \%$ & $\mathrm{RSD}=0.74 \%$ \\
\hline & $\bar{x}=98.64$ & $\bar{x}=97.57$ & $\bar{x}=99.20$ \\
\hline \multirow{3}{*}{ Recovery $100 \%(\%)$} & $S_{\mathrm{x}}=0.537$ & $S_{\mathrm{x}}=0.243$ & $S_{\mathrm{x}}=1.532$ \\
\hline & $\mathrm{RSD}=0.54 \%$ & $\mathrm{RSD}=0.25 \%$ & $\mathrm{RSD}=1.54 \%$ \\
\hline & $\bar{x}=101.69$ & $\bar{x}=98.90$ & $\bar{x}=99.18$ \\
\hline \multirow[t]{3}{*}{ Recovery $120 \%(\%)$} & $S_{\mathrm{x}}=2.375$ & $S_{\mathrm{x}}=0.540$ & $S_{\mathrm{x}}=1.222$ \\
\hline & $\mathrm{RSD}=2.34 \%$ & $\mathrm{RSD}=0.55 \%$ & $\mathrm{RSD}=1.23 \%$ \\
\hline & $\bar{x}=0.230$ & $\bar{x}=0.258$ & $\bar{x}=0.210$ \\
\hline \multirow[t]{3}{*}{ Precision $50 \% \mathrm{c}(\mathrm{mg} / \mathrm{mL})$} & $S_{\mathrm{x}}=0.0014$ & $S_{\mathrm{x}}=0.0020$ & $S_{\mathrm{x}}=0.0050$ \\
\hline & $\mathrm{RSD}=0.62 \%$ & $\mathrm{RSD}=0.77 \%$ & $\mathrm{RSD}=2.38 \%$ \\
\hline & $\bar{x}=0.458$ & $\bar{x}=0.498$ & $\bar{x}=0.425$ \\
\hline \multirow[t]{3}{*}{ Precision $100 \% \mathrm{c}(\mathrm{mg} / \mathrm{mL})$} & $S_{\mathrm{x}}=0.0049$ & $S_{\mathrm{x}}=0.0075$ & $S_{\mathrm{x}}=0.0025$ \\
\hline & $\mathrm{RSD}=1.06 \%$ & $\mathrm{RSD}=1.52 \%$ & $\mathrm{RSD}=0.59 \%$ \\
\hline & $\bar{x}=0.692$ & $\bar{x}=0.750$ & $\bar{x}=0.628$ \\
\hline \multirow{2}{*}{ Precision $150 \% \mathrm{c}(\mathrm{mg} / \mathrm{mL})$} & $S_{\mathrm{x}}=0.0030$ & $S_{\mathrm{x}}=0.0050$ & $S_{\mathrm{x}}=0.0025$ \\
\hline & $\mathrm{RSD}=0.44 \%$ & RSD $=0.67 \%$ & $\mathrm{RSD}=0.40 \%$ \\
\hline
\end{tabular}

we chose this model considering lower efficiency of the estimators. In the case of tryptamine, the presence of autocorrelation was demonstrated using the Lagrange test, because the Durbin-Watson test was not conclusive. Homogeneity of variance of random components in the proposed model was checked and confirmed using Bartlett test $(p$ value $>0.05)$ (Table 2).
Samples prepared for analysis were determined in five replicates. The results of the studies carried out by Muszyńska et al. [6] were used as reference (control) values. The analysis confirmed the presence of three indole compounds: L-tryptophan, 5-hydroxy-L-tryptophan, and tryptamine (Tables 3 and 4). The results obtained using TLC with densitometric detection were expressed as indole compounds content per $100 \mathrm{~g}$ dry mass of 
Table 2. Validation results obtained in the experiments: linear and square fit

\begin{tabular}{|c|c|c|c|c|c|c|}
\hline Name of the substance & & $\begin{array}{l}\text { Equation of the form: } \\
\qquad P=f(m)\end{array}$ & $R^{2}$ & $\begin{array}{c}\text { Shapiro-Wilk } \\
\text { test }(p)\end{array}$ & Durbin-Watson test & $\begin{array}{l}\text { Bartlett } \\
\text { test }(p)\end{array}$ \\
\hline \multirow[t]{3}{*}{ Tryptamine } & Linear model $(p)$ & $\begin{array}{c}P=4723.6 \cdot m+367 \\
\quad(0.000)(0.003)\end{array}$ & 0.9894 & $\begin{array}{l}0.906>0.874 \\
(0.136)\end{array}$ & $0.378<1.045$ & $\begin{array}{c}0.373 \\
(0.541)\end{array}$ \\
\hline & Quadratic model $(p)$ & $\begin{array}{c}P=1076.1 \cdot m^{2}+6392.8 \cdot m-92.0 \\
(0.000)(0.000)(0.131)\end{array}$ & 0.9988 & $\begin{array}{c}0.981>0.874 \\
(0.976)\end{array}$ & $\begin{array}{c}1.045<1.320>1.350 \\
\text { Lagrange test: } \\
(p) 5.031>3.841 \\
(0.025)\end{array}$ & $\begin{array}{r}0.167 \\
(0.683)\end{array}$ \\
\hline & Mandel's test $(p)$ & \multicolumn{5}{|c|}{$99.7(0.000)$} \\
\hline \multirow[t]{3}{*}{ 5-Hydroxy-L-tryptophan } & Linear model $(p)$ & $\begin{array}{c}P=4880.2 \cdot m-111.3 \\
(0.000)(0.278)\end{array}$ & 0.9912 & $\begin{array}{c}0.898>0.897 \\
(0.054)\end{array}$ & $1.799>1.391$ & $\begin{array}{c}2.381 \\
(0.123)\end{array}$ \\
\hline & Quadratic model $(p)$ & $\begin{array}{c}P=-676.0 \cdot m^{2}+6022.7 \cdot m-412.5 \\
(0.005)(0.000)(0.004)\end{array}$ & 0.9945 & $\begin{array}{l}0.946>0.897 \\
\quad(0.373)\end{array}$ & $0.715<1.158$ & $\begin{array}{c}0.157 \\
(0.692)\end{array}$ \\
\hline & Mandel's test $(p)$ & \multicolumn{5}{|c|}{$10.7(0.005)$} \\
\hline \multirow[t]{3}{*}{ L-Tryptophan } & Linear model $(p)$ & $\begin{aligned} P= & 4703.8 \cdot m+307.6 \\
& (0.000)(0.002)\end{aligned}$ & 0.9922 & $\begin{array}{l}0.971>0.887 \\
\quad(0.851)\end{array}$ & $0.978<1.106$ & $\begin{array}{l}1.923 \\
(0.165)\end{array}$ \\
\hline & Quadratic model $(p)$ & $\begin{aligned} P=- & -885.6 \cdot m^{2}+6177.5 \cdot m-75.5 \\
& (0.000)(0.000)(0.178)\end{aligned}$ & 0.9988 & $\begin{array}{l}0.965>0.887 \\
(0.944)\end{array}$ & $2.441>1.371$ & $\begin{array}{c}3.293 \\
(0.070)\end{array}$ \\
\hline & Mandel's test $(p)$ & \multicolumn{5}{|c|}{$79.8(0.000)$} \\
\hline
\end{tabular}

Table 3. Content of indole compounds in fruiting bodies (control) of A. bisporus and I. badia per $\mathrm{mg} / 100 \mathrm{~g}$ of lyophilizate

\begin{tabular}{lcc}
\hline Sample & Tryptamine & L-Tryptophan \\
\hline Agaricus bisporus control & $\bar{x}=19.31$ & $\bar{x}=19.25$ \\
& $S_{\mathrm{x}}=0.475$ & $S_{\mathrm{x}}=0.455$ \\
Imleria badia control & $\mathrm{RSD}=2.46 \%$ & $\mathrm{RSD}=2.36 \%$ \\
& $\bar{x}=24.22$ & $\bar{x}=84.43$ \\
& $S_{\mathrm{x}}=0.472$ & $S_{\mathrm{x}}=0.686$ \\
$\mathrm{RSD}=1.95 \%$ & $\mathrm{RSD}=0.81 \%$
\end{tabular}

$\bar{x}$, mean value; $S_{\mathrm{x}}$, standard deviation; RSD, relative standard deviation

the biomass from in vitro cultures. In the case of $A$. bisporus culture using medium supplemented with serine, L-tryptophan was determined only in the sample from biomass cultivated on medium enriched with $0.5 \mathrm{~g} / \mathrm{L}$ serine and its content was established at $42.02 \mathrm{mg} / 100 \mathrm{~g}$ d.m. (dry mass). Also, tryptamine was detected only in the aforementioned sample and its amount was $113.77 \mathrm{mg} / 100 \mathrm{~g}$ d.m. In contrast, 5-hydroxy-L-tryptophan was determined in all A. bisporus samples enriched with serine and the content of this compound ranged from 17.92 to $46.02 \mathrm{mg} /$ $100 \mathrm{~g} \mathrm{~d} . \mathrm{m}$. The amount of 5-hydroxy-L-tryptophan per $100 \mathrm{~g}$ dry matter increased proportionally to the increase in serine concentration used to enrich the medium. In the biomass obtained from $A$. bisporus mycelial culture using medium enriched with anthranilic acid, L-tryptophan was detected in three out of four analyzed samples and its content ranged from 22.34 to $66.79 \mathrm{mg} / 100 \mathrm{~g}$ d.m. The highest concentration of this compound was found in the sample enriched with anthranilic acid at the concentration of $0.5 \mathrm{~g} / \mathrm{L}$ medium. Tryptamine was determined only in the sample enriched with anthranilic acid at the concentration of $0.75 \mathrm{~g} / \mathrm{L}$ medium, and its amount was set at $46.80 \mathrm{mg} / 100 \mathrm{~g}$ d.m.

In contrast, 5-hydroxy-L-tryptophan was found in most of the analyzed material except for the sample derived from in vitro cultured $A$. bisporus using medium enriched with anthranilic acid at the concentration of $0.25 \mathrm{~g} / \mathrm{L}$ medium. The content of the tested compound ranged from $9.56 \mathrm{mg} / 100 \mathrm{~d} . \mathrm{m}$. $(0.1 \mathrm{~g} / \mathrm{L}$ anthranilic acid) to 154.64 ( $0.5 \mathrm{~g} / \mathrm{L}$ anthranilic acid).

For A. bisporus cultures, the largest total amount of indole compounds (exceeding $200 \mathrm{mg} / 100 \mathrm{~g} \mathrm{~d} . \mathrm{m}$.) was determined in the sample obtained from biomass cultured with the use of medium enriched with anthranilic acid at the concentration of

Table 4. Indole compounds content in biomass from in vitro cultures of Agaricus bisporus and Imleria badia per mg/100 g lyophilizate

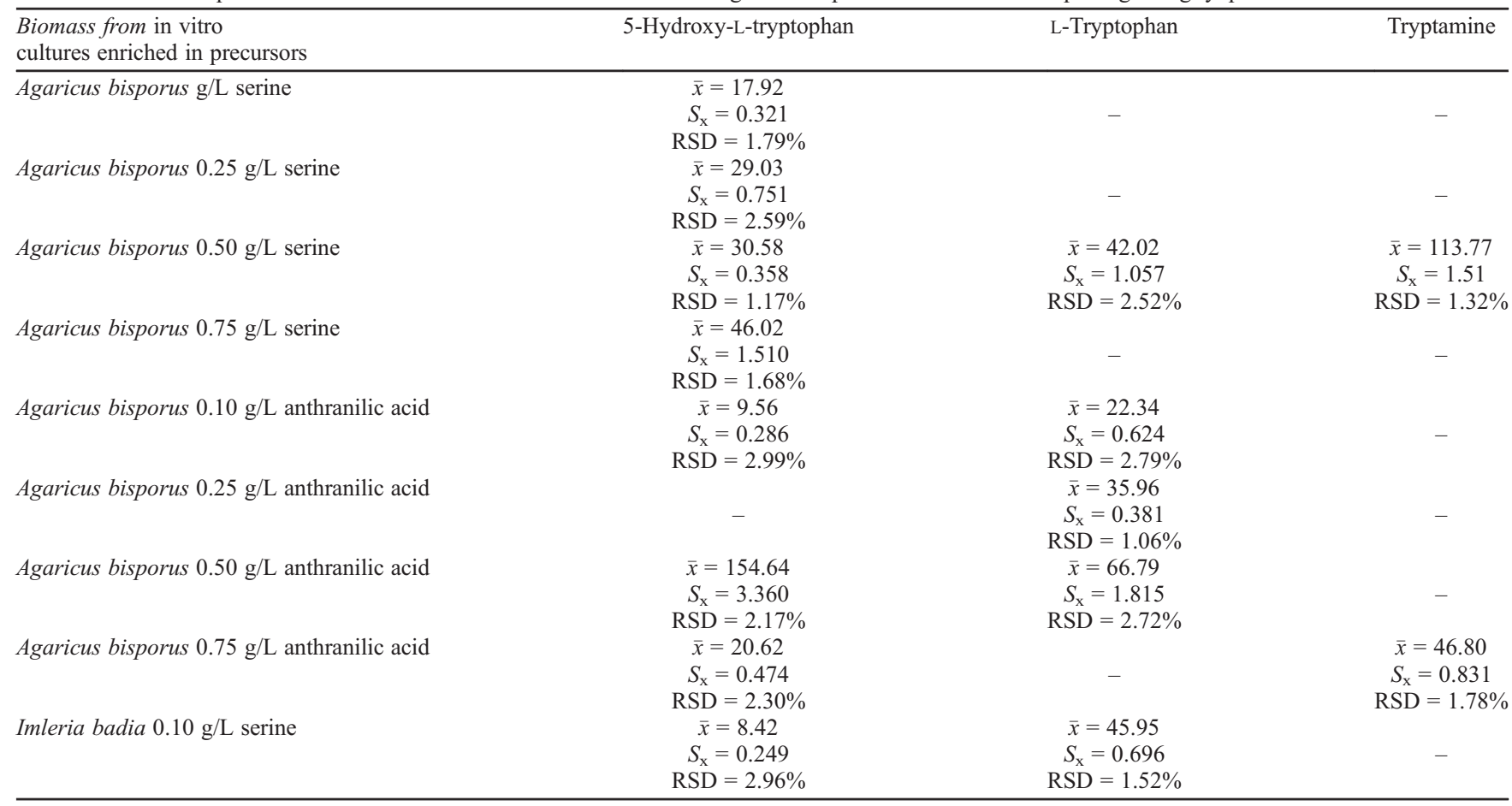


Table 4. (contd.)

\begin{tabular}{|c|c|c|c|}
\hline $\begin{array}{l}\text { Biomass from in vitro } \\
\text { cultures enriched in precursors }\end{array}$ & 5-Hydroxy-L-tryptophan & L-Tryptophan & Tryptamine \\
\hline \multirow{3}{*}{ Imleria badia $0.25 \mathrm{~g} / \mathrm{L}$ serine } & $\bar{x}=7.81$ & $\bar{x}=22.82$ & \\
\hline & $S_{\mathrm{x}}=0.222$ & $S_{\mathrm{x}}=0.488$ & - \\
\hline & $\mathrm{RSD}=2.84 \%$ & $\mathrm{RSD}=2.14 \%$ & \\
\hline \multirow[t]{3}{*}{ Imleria badia $0.50 \mathrm{~g} / \mathrm{L}$ serine } & & $\bar{x}=14.53$ & \\
\hline & - & $S_{\mathrm{x}}=0.173$ & - \\
\hline & & $\mathrm{RSD}=1.19 \%$ & \\
\hline \multirow[t]{3}{*}{ Imleria badia $0.75 \mathrm{~g} / \mathrm{L}$ serine } & $\bar{x}=13.89$ & $\bar{x}=16.71$ & \\
\hline & $S_{\mathrm{x}}=0.329$ & $S_{\mathrm{x}}=0.303$ & - \\
\hline & $\mathrm{RSD}=2.37 \%$ & $\mathrm{RSD}=1.82 \%$ & \\
\hline \multirow[t]{3}{*}{ Imleria badia $0.10 \mathrm{~g} / \mathrm{L}$ anthranilic acid } & $\bar{x}=16.38$ & $\bar{x}=10.27$ & \\
\hline & $S_{\mathrm{x}}=0.299$ & $S_{\mathrm{x}}=0.149$ & - \\
\hline & $\mathrm{RSD}=1.83 \%$ & $\mathrm{RSD}=1.45 \%$ & \\
\hline \multirow[t]{3}{*}{ Imleria badia $0.25 \mathrm{~g} / \mathrm{L}$ anthranilic acid } & $\bar{x}=15.19$ & $\bar{x}=124.49$ & \\
\hline & $S_{\mathrm{x}}=0.348$ & $S_{\mathrm{x}}=0.785$ & - \\
\hline & $\mathrm{RSD}=2.29 \%$ & $\mathrm{RSD}=0.63 \%$ & \\
\hline \multirow{3}{*}{ Imleria badia $0.50 \mathrm{~g} / \mathrm{L}$ anthranilic acid } & $\bar{x}=14.94$ & $\bar{x}=83.00$ & $\bar{x}=254.12$ \\
\hline & $S_{\mathrm{x}}=0.166$ & $S_{\mathrm{x}}=0.985$ & $S_{\mathrm{x}}=1.740$ \\
\hline & $\mathrm{RSD}=1.11 \%$ & $\mathrm{RSD}=1.19 \%$ & $\mathrm{RSD}=0.68 \%$ \\
\hline \multirow[t]{3}{*}{ Imleria badia $0.75 \mathrm{~g} / \mathrm{L}$ anthranilic acid } & & $\bar{x}=31.13$ & \\
\hline & - & $S_{\mathrm{x}}=0.406$ & - \\
\hline & & $\mathrm{RSD}=1.31 \%$ & \\
\hline
\end{tabular}

$0.5 \mathrm{~g} / \mathrm{L}$. The total amount of indole compounds at the high concentration ( $186.37 \mathrm{mg} / 100 \mathrm{~g} \mathrm{~d} . \mathrm{m}$.) was also determined in a sample from medium enriched with serine at the concentration of $0.5 \mathrm{~g} / \mathrm{L}$. In both cases, the established amount, several times higher exceeded the content of indole compounds in the control sample. Higher concentration of indole compounds was also found in the biomass from cultures enriched with anthranilic acid at the concentration of $0.75 \mathrm{~g} / \mathrm{L}$ medium (67.42 mg/100 g d.m.).

For I. badia cultures, most of indole compounds were determined in samples from culture medium enriched with anthranilic acid at the concentration of $0.5 \mathrm{~g} / \mathrm{L}$ medium, and their total amount was as high as $352.06 \mathrm{mg} / 100 \mathrm{~g}$ d.m. On the other hand, serine addition to the medium did not significantly affect the content of indole compounds - only in one sample, a slight elevation was detected $(0.1 \mathrm{~g} / \mathrm{L}$ serine addition). L-Tryptophan was determined in all samples obtained from I. badia biomass. The highest concentration of this compound determined was $124.49 \mathrm{mg} / 100 \mathrm{~g} \mathrm{~d} . \mathrm{m}$. and was obtained from I. badia culture medium with anthranilic acid supplementation at $0.25 \mathrm{~g} / \mathrm{L}$ medium. The presence of 5-hydroxy-L-tryptophan was found in most samples. However, it was not found in I. badia biomass obtained from in vitro cultures cultivated on medium enriched with serine at $0.5 \mathrm{~g} / \mathrm{L}$ and anthranilic acid at $0.75 \mathrm{~g} / \mathrm{L}$ medium. The most abundant in 5-hydroxy-L-tryptophan was I. badia biomass from cultures cultivated on medium with anthranilic acid at $0.1 \mathrm{~g} / \mathrm{L}$ medium ( $16.38 \mathrm{mg} / 100 \mathrm{~g} \mathrm{~d} . \mathrm{m}$.). The presence of tryptamine was demonstrated in only one sample, in which in vitro I. badia cultures were enriched with anthranilic acid at the concentration of $0.5 \mathrm{~g} / \mathrm{L}$ medium $(254.12 \mathrm{mg} / 100 \mathrm{~d} . \mathrm{m}$.).

The addition of organic compounds to the medium, i.e., serine or anthranilic acid, resulted in increase in the total content

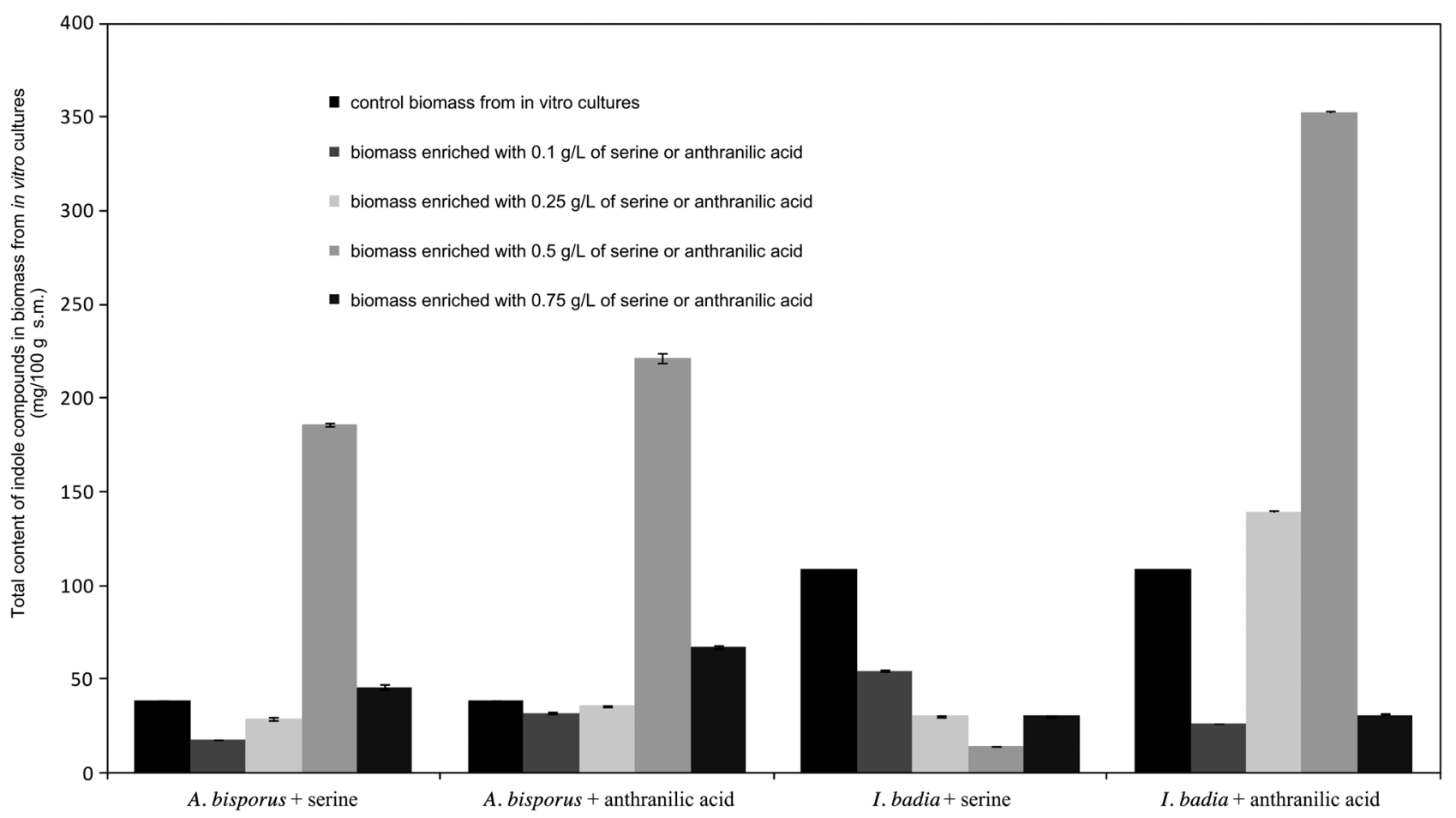

Figure 3. A graph summarizing the total content of indole compounds in the biomass from in vitro cultures of Agaricus bisporus and Imleria badia without or enriched serine-anthranilic acid 
of indole compounds in the biomass compared to control; however, this increase was not found in every sample (Figure 3). The whole experiment showed that both biomass of $A$. bisporus and I. badia contained increased amount of indole compounds under the influence of appropriate supplementation of serine or anthranilic acid. The results demonstrated that both mushroom species for which enriched medium is used as well as the compound used for the enrichment are relevant. The addition of organic compounds at the appropriate concentration to the medium, which are potential precursors of indole compounds, allows to increase their total content in biomass obtained from in vitro cultures. This creates new perspectives for further research evaluating the impact of medium modification toward appropriate qualitative and quantitative composition of indole compounds in the obtained lyophilized biomass and its subsequent use as a potential source of these compounds.

\section{Conclusion}

This is the first report that shows that medium modification through serine or anthranilic acid supplementation affects the content of indole compounds in the resulting biomass. The concentration of the additive added to the medium is also important in the context of quantitative and qualitative content of these compounds in the resulting biomass. It indicates that modification of medium for mycelial cultures may be crucial for the potential production of lyophilized biomass containing specific indole compounds at suitable amounts that can be used in the supplementation of indole derivatives.

\section{Conflict of Interest}

The authors have declared no conflict of interest.

\section{References}

1. Muszyńska, B., Jadalne gatunki grzybów źródtem substancji dietetycznych i leczniczych; Ośrodek Umea Shinoda - Kuracejo: Krakow, 2012, p. 109.

2. Kała, K.; Muszyńska, B.; Zając, M.; Krężałek, R.; Opoka, W. Int. J. Med. Mushrooms 2016, 18, 155.

3. Muszyńska, B.; Komendacki, P.; Kała, K.; Opoka, W.; Rojowski, J. Med. Inter. Rev. 2014, 2, 82.

4. Muszyńska, B. and Sułkowska-Ziaja, K. Food Chem. 2012, 132, 455.

5. Muszyńska, B.; Sułkowska-Ziaja, K.; Ekiert, H. J. Food Sci. Tech.

2013, 50, 1233

6. Muszyńska, B.; Sułkowska-Ziaja, K.; Wójcik, A. Mycoscience 2013, 54, 321.

7. Muszyńska, B.; Sułkowska-Ziaja, K.; Maślanka, A.; Rojowski, J.; Opoka, W.; Łojewski, M. Acta Chromatogr. 2016, 28, 223.

8. Heleno, S. A.; Ferreira, R. C.; Antonio, A. L.; Queiroz, M. J. R. P.;

Barros, L.; Ferreira, I. C. F. R. Food Biosci. 2015, 11, 48.

9. Jaworska, G.; Pogoń, K.; Skrzypczak, A.; Bernaś, E. J. Food Sci. Tech.

2015, 52, 7944.

10. Kojta, A. K. and Falandysz, J. Food Chem. 2016, 200, 206

11. Muszyńska, B.; Sułkowska-Ziaja, K.; Ekiert, H. Acta Sci. Pol-Hortoru.

2013, 12, 107 .

12. Falandysz, J.; Zalewska, T.; Krasińska, G.; Apanel, A.; Wang, Y.; Pankavec, S. Appl. Microbiol. Biot. 2015, 99, 8217.

13. Muszyńska, B.; Sułkowska-Ziaja, K.; Łojewski, M.; Opoka, W.; Zając, M.; Rojowski, J. Med. Inter. Rev. 2013, 101, 170.

14. Elmastas, M.; Isildak, O.; Turkekul, I.; Temur, N. J. Food Compos. Anal. 2007, 20, 337.

15. Cheah, I. K. and Halliwell, B. BBA-Mol. Cell Basis Dis. 2012, 1822, 784.

16. Chen, S. Y.; Ho, K. J.; Hsieh, Y. J.; Wang, L. T.; Mau, J. L. LWT Food

Sci. Technol. 2012, 47, 274.

17. Calvo, M. S.; Mehrotra, A.; Beelman, R. B.; Nadkarni, G.; Wang, L.; Cai,

W.; Goh, B. Ch.; Kalaras, M. D.; Uribarri, J. Plant Food Hum. Nutr. 2016, 71, 245.

18. Batterbury, M.; Tebbs, C. A.; Rhodes, J. M.; Grierson, I. Exp. Eye Res. 2002, 74, 361.

19. Chang, H. H.; Chien, P. J.; Tong, M. H.; Sheu, F. Food Chem. 2007, 105, 597.

20. Greene, W. C.; Fleisher, T. A.; Waldmann, T. A. J. Immunol. 1981, 126, 580

21. Parslew, R.; Jones, K. T.; Rhodes, J. M.; Sharpe, G. R. Brit. J. Dermatol. 1999, 140,56

22. Wang, H. X. and Ng, T. B. Planta Med. 2001, 67, 669

23. Yu, L.; Fernig, D. G.; Smith, J. A.; Milton, J. D.; Rhodes, J. M. Cancer Res. 1993, 53, 4627 .

24. Muszyńska, B.; Sułkowska-Ziaja, K.; Hałaszczuk, P.; Krężałek, R.; Łojewski, M. Folia Biol. Oecol. 2014, 10, 66.

25. Oddoux, L., Recherches sur les mycéliums secondaires des Homobasidiés en culture pure; Imprimerie de Trevoux: Lyon, 1957

26. Muszyńska, B.; Sułkowska-Ziaja, K.; Ekiert, H. Pharmazie 2009, 64, 479.

27. ICH-Q2 (R1) Validation and Analytical Procedures: Text and Methodology, International Conference on Harmonization, Geneva, November 2005.

28. Komsta, L. J. AOAC Int. 2012, 95, 669. 